\title{
The Comparative Effect of Capsella bursa-pastoris and Mefenamic Acid on Sexual Function of Copper IUD Users
}

\author{
Fahimeh Sehhati ${ }^{1}$, Mojgan Mirghafourvand ${ }^{2}$, Roya Hamzehpour ${ }^{3 *}$
}

\begin{abstract}
Objectives: Intrauterine device (IUD) is one of the most common methods of pregnancy prevention that is widely used in the world. Bleeding is one of the key reasons of stopping the use of IUD. Vaginal bleeding can be occurred due to the reduction of adequate motivation and functioning of neuroendocrine system and subsequent hormones (oxytocin, serotonin); and accordingly sexual functioning would be decreased. Therefore, the hemostatic impact of Capsella bursa-pastoris through several mechanisms can play a leading role in increasing the orgasm and sexual responses. The aim of current study was to determine the impact of C. bursa-pastoris on sexual functioning of females having copper IUD.

Materials and Methods: This triple blind clinical trial was done in 2014 on 90 females visiting healthcare centers of Ardebil city, Iran. Women were complaining about excessive menstrual bleeding which occurred at least 3 months after placing IUDs. The first group received C. bursa-pastoris $(700 \mathrm{mg}$ ) and the second group received mefenamic acid $(500 \mathrm{mg})$ from first day of menstruation till bleeding completion, one every 8 hours. The questionnaire of sexual functioning was completed by the participants prior and 3 months after the treatment. The analysis of covariance (ANCOVA) test was used for comparing sexual functioning after the intervention among the studied groups with some adjustments on baseline scores.

Results: Mean (standard deviation) score of sexual functioning in mefenamic acid group was 23.39 (4.18) before the intervention which was increased to $24.24 \pm 3.45$ after applying intervention. In C. bursa-pastoris group, mean (standard deviation) score of sexual functioning was 21.40 (4.70) before the intervention which was increased to $24.85 \pm 3.81$ after applying intervention. According to the findings of study, mefenamic acid and C. bursa-pastoris were effective in improving the sexual functioning, but increase of sexual functioning score after the intervention was significant in the C. bursa-pastoris group (the justified mean difference: $0.60,95 \%$ CI [-0.91-2.13], $P=0.01)$.

Conclusions: Capsella bursa-pastoris can be more effective compared to chemical drugs including mefenamic acid in increasing the sexual functioning of females with IUD.

Keywords: Mefenamic acid, Capsella bursa-pastoris, Sexual functioning, Copper IUD
\end{abstract}

\section{Introduction}

Intrauterine device (IUD) is one of the most common ways of pregnancy prevention which is widely used in the world. About $13.9 \%$ of population of developed countries and $8.9 \%$ of population of developing countries use IUDs. According to the world statistics in 2013, approximately $7.6 \%$ of females in pregnancy ages use IUD (1). The IUDs containing copper were introduced to the world markets in late 1960s and nowadays are available in various types (2), from which Tcu380A is the most effective kind (3). IUD is for longtime use and has been considered as an irreversible pregnancy prevention method for 10 years (4). IUDs are not only effective and safe for pregnancy prevention, but also they have very important health advantages; for instance, IUD protects endometrium against cancer (5). In addition, copper IUDs do not create any disorders in pregnancy and the rate of unexpected pregnancies is less in IUD users compared to the users of other methods (6).

Despite the wide use of IUD, early interruption of this method is considered a major problem and early IUD exodus causes pain and bleeding along with menstruation (7). Besides, use of IUD with increasing irregular uterine bleedings decreases the number of sexual intercourses and accordingly the sexual functioning (8). Sexual disorders may result from mental and physical factors. In cases with a physical reason for sexual problem, mental factors may play secondary role in complicating the condition and can cause disorders in sexual responses and dysfunctions (9). Paying attention to the sexual health in users of pregnancy prevention methods can have a role in the continuous use of prevention methods. Lack of attention to females' sexual health leads to the incorrect use of pregnancy prevention methods and accordingly unwanted pregnancies, induced and unhealthy abortions, and some other problems (10).

Using non-steroidal anti-inflammatory drugs except 
aspirin, including mefenamic acid is considered the first line of treatment for bleeding because of fewer side effects and its low price (11). These drugs are ineffective in $10 \%$ $20 \%$ of the patients (12) and some patients are banned to use them. Therefore, there is a need of safe treatment for bleeding in the cases with copper IUDs.

Capsella bursa-pastoris is an annual and ruderal flowering plant from Cruciferae's family (13) and contains minerals, vitamin A, ascorbic acid, protein, linoleic acid, polyunsaturated $\omega 3$ fatty acid, magnesium, iron, vitamin $\mathrm{B}$ and $\mathrm{C}$ (14). In texts related to herbs and traditional medicine, this plant has been considered as an antibleeding and astringent medicine and its useful effects have been reported in chronic menorrhagia and uterine bleeding treatment (13-15), anxiety treatment, and rapid recovery of wounds $(16,17)$. C. bursa-pastoris can be effective on smooth muscles of uterus and increase their contraction. Having hypochlorite effect, it is used orally for the treatment of uterus and severe bleedings $(18,19)$. The hemostatic effects of this plant are exerted through several mechanisms including stimulation of uterus contractions, contraction of capillaries, stimulation of prothrombin production, and reduction of fragility in capillaries (20). Moreover, C. bursa-pastoris has oxytocin synergic effects (21), and oxytocin plays an important role in human's excitement, orgasm and increase of sexual responses $(22,23)$. It seems that due to these biochemical features, oxytocin can be effective in bleeding amount and accordingly sexual functioning. Despite the effect of sexual relationships on human's physical and mental health, paying inadequate attention to sexual issues in Iran is completely conspicuous. In the same vein, failure of pregnancy prevention methods can be due to sexual disorders resulted from pregnancy prevention disorders. All these reasons provided motivation for designing a research with the aim of determining the effect of $C$. bursa-pastoris on sexual functioning in copper IUD users to improve the score of sexual function, avoid early removal of IUD and increase the acceptance of this tool in community.

\section{Materials and Methods}

Study Type and Participants

This study was part of a controlled random triple blind clinical trial in which sexual functioning was investigated as a secondary consequence. The studied population were the females in the age range of 15-40 years visiting healthcare centers of Ardebil city, Iran, since early March till July 2015.

The eligible criteria for doing the study included: abnormal menstrual bleeding at least for 3 months after IUD insertion, absence of systemic diseases according to the individual's remarks (thyroid disease, myoma, hyperprolactinaemia, etc), absence of uterine myoma according to the individual's remarks, absence of drug reaction to mefenamic acid, regular menstrual cycle before
IUD insertion, a minimum proficiency level at reading and writing, having inclination toward participating in the study, and having informed consent letter.

\section{Sample Size}

According to the available data from a previous study by Mirghafourvand et al (24), and considering the sexual functioning score before the intervention $(\mathrm{ml}=65.9)$ and with presumption of $20 \%$ increase in sexual functioning score $(\mathrm{m} 2=79.08, \quad \mathrm{sd} 1=\mathrm{sd} 2=8.15$ and $\alpha=0.05$, power $=95 \%$ ), the sample size for each group was considered 39 , and with possibility of $10 \%$ decrease, the final sample size was considered 45 .

\section{Randomization and Intervention}

The samples were divided into 2 groups of mefenamic acid $(n=46)$ and C. bursa-pastoris $(n=44)$ by using computerized random numbers and through quadruple and sextet blockings. The division order was done by an individual who was not involved in the study and by the use of randomizer program. For the members in $C$. bursa-pastoris group, 3 pills each containing $700 \mathrm{mg}$ the powder of plant (the total of the plant) for duration of 3 cycles (since the first day of period till day 7 or at the end of bleeding in cases less than 7 days) were prescribed and for the mefenamic acid group, the pills containing $500 \mathrm{mg}$ were prescribed with the same instruction. For preparing the C. bursa-pastoris, bursa-pastoris plant was purchased from Tabriz drug market during April 2015 and after identification, it was powdered by grinder in botany laboratory of the Faculty of Pharmacy at Tabriz University of Medical Sciences. Then, according to the considered dose of pills, the appropriate amount of bursa-pastoris plant was mixed with appropriate amount of gelatin liquid and sifted from mesh sieve 10 in a wet state and after that, about $30 \%$ of weighted microcrystalline powder was added to the prepared granules and an amount of $3 \%$ sodium starch glycolate as an opener and $1 \%$ magnesium stearate as a lubricant were added and pressed by a machine into pills containing $700 \mathrm{mg}$ bursa-pastoris plant. The mefenamic acid pills were prepared according to the same method each pill containing $500 \mathrm{mg}$ mefenamic acid. The required mefenamic acid powder was prepared by Alhavi Pharmaceutical Co., Tehran, Iran. Both of the pills were the same in terms of appearance (shape, color, smell).

\section{Sampling}

Sampling was done after that Ethics Code was obtained from the Ethics Committee of Tabriz University of Medical Sciences. Ardebil has 21 healthcare centers in total and sampling was done from 14 centers located in various areas of Ardebil with different social and economic statuses. At the first stage, a checklist was prepared according to IUD offices by females at the age range of 15-45 who had IUD and 3 months had passed form their IUD insertion. Then, 
these people were contacted, and was asked from the ones who were dissatisfied with bleeding due to copper IUD to visit the corresponding healthcare center in the case of having inclination toward participating in the study. For considering research-ethics issues, at the beginning of the study, the objectives, design and methodology were explained to the qualified women and the conditions of inclusion in the study was described to the participants. After obtaining the written informed consent letter, social-individual characteristics questionnaire and Higham chart along with required explanations for filling it out and the same sanitary napkin were made available to people by the researcher and they were requested to bring back the completed questionnaires after one month. According to the Higham chart, individuals who obtained scores higher than 100 were entered into the study and the sexual functioning questionnaire was filled for them. For each participant, there was 3 small packets containing drugs that each of them was prepared for one month and the small 3 packets were inside a big pale and tandem packet which was numbered in order. After the end of third period bleeding, and after the intervention initiation, the packets of drugs were received and the sexual functioning questionnaires were filled out again. It is noteworthy that according to the reports of studies, for achieving an acceptable result from the drugs, at least 3 months is demanded and at most it is achieved during 6 months or more. Accordingly, in this study, prescription of drugs was continued for 3 cycles. For assuring drug's use and completing the questionnaires, the participants were examined every 2 weeks through phone contacts. The questionnaire was filled out by the participant herself.

\section{Data Collection Tool}

In this study for data collection, social-individual questionnaire, and sexual functioning (FSFI) and secondary side effects questionnaire were used. Higham graphic chart's questionnaire or Pictorial Blood Lost Assessment Chart (PBAC) were used for bleeding assessment. Higham chart is a chart in which the first horizontal row shows the number of period days and the vertical row shows the pads soaked in blood with 3 degrees of mild, moderate, and severe. For the mild degree, coefficient 1; for moderate degree, coefficient 5; and for severe degree, coefficient 20 (pads completely soaked in blood) were considered. In addition, small clots (size of a $1 \mathrm{p}$ coin) and large clots (size of a 50p coin) are scored as 1 point and 5 points, respectively and for the removal of blood flow (to contaminate underwear or blood flow in restroom), score 5 were considered. At the end of period, each sign was multiplied by the corresponding coefficient and the calculated numbers were collected and the total score was obtained. The score of 100 and above, referred to bleeding more than $80 \mathrm{~mm}$ and score less than 100 showed less bleeding. This method with sensitivity of $86 \%$ and specificity of $89 \%$ was an effective method for separation of menorrhagia from normal menstrual bleeding. The reliability and validity of Higham chart were verified by Moukhah et al (25) in Iran.

Sexual functioning was measured through a 19-case comprehensive questionnaire developed by Rosen et al (26) (Female Sexual Functioning Index). The reliability and validity of its Persian version was verified by Mohammadi et al (27). This standard questionnaire measures the sexual functioning in 6 domains of desire, arousal, humidifying, orgasm, sexual satisfaction and pain during the recent 4 weeks. These sub-branches, have response spectra of 0,5 , and 1 . Score 0 indicates the absence of sexual relationship during the last 4 weeks and score 5 indicates the maximum satisfaction from sexual relationship in each domain. According to the instructions of questionnaire designer, the scores of each domain can be achieved through adding up the scores of questions in each domain, then their multiplication by the factor number. By adding up the scores of these 6 domains, the total score scale is obtained. Balancing the scores, the maximum score for each domain equals to 6 and for the total scale, it would be 36 . Zero is demonstrative of the issue that the person did not have sexual activity during the last 4 weeks and high score demonstrates more desirable sexual functioning.

\section{Data Analysis}

The data were analyzed using SPSS version 21.0. Normality of the quantitative variables were examined using Kolmogorov-Smirnov test which was normal. For comparison of individual-social characteristics among the groups, independent $t$ test, Chi-square, Fisher exact test, and round chi-square were used. For comparing the sexual functioning score, before intervention, independent $t$ test and after intervention, analysis of covariance (ANCOVA) test were used with controlling the base values. A $P$ value $<0.05$ was considered significant.

\section{Results}

Sampling and pursuing the research samples was initiated since early April 2015 and continued till late November 2015. In total, among 1036 women who were qualified according to IUD offices of healthcare centers, 385 women due to lack of visiting centers, 268 women due to unwillingness to take part in the study (the major reason was mentioned their husband's dissatisfaction) and 293 women due to lack of criteria for entering into the study including absence of reading and writing skills, presence of uterine myoma, obtaining scores less than Higham chart, etc were excluded from the study. The remained 90 women were divided into 2 groups of mefenamic acid and bursa-pastoris. In total, 46 females in mefenamic acid group and 44 females in bursa-pastoris group successfully completed 3 months of pursuing (Figure 1).

In this study, 90 women were analyzed and sample loss did not occur in the groups. There was not any significant statistical difference between 2 groups considering 


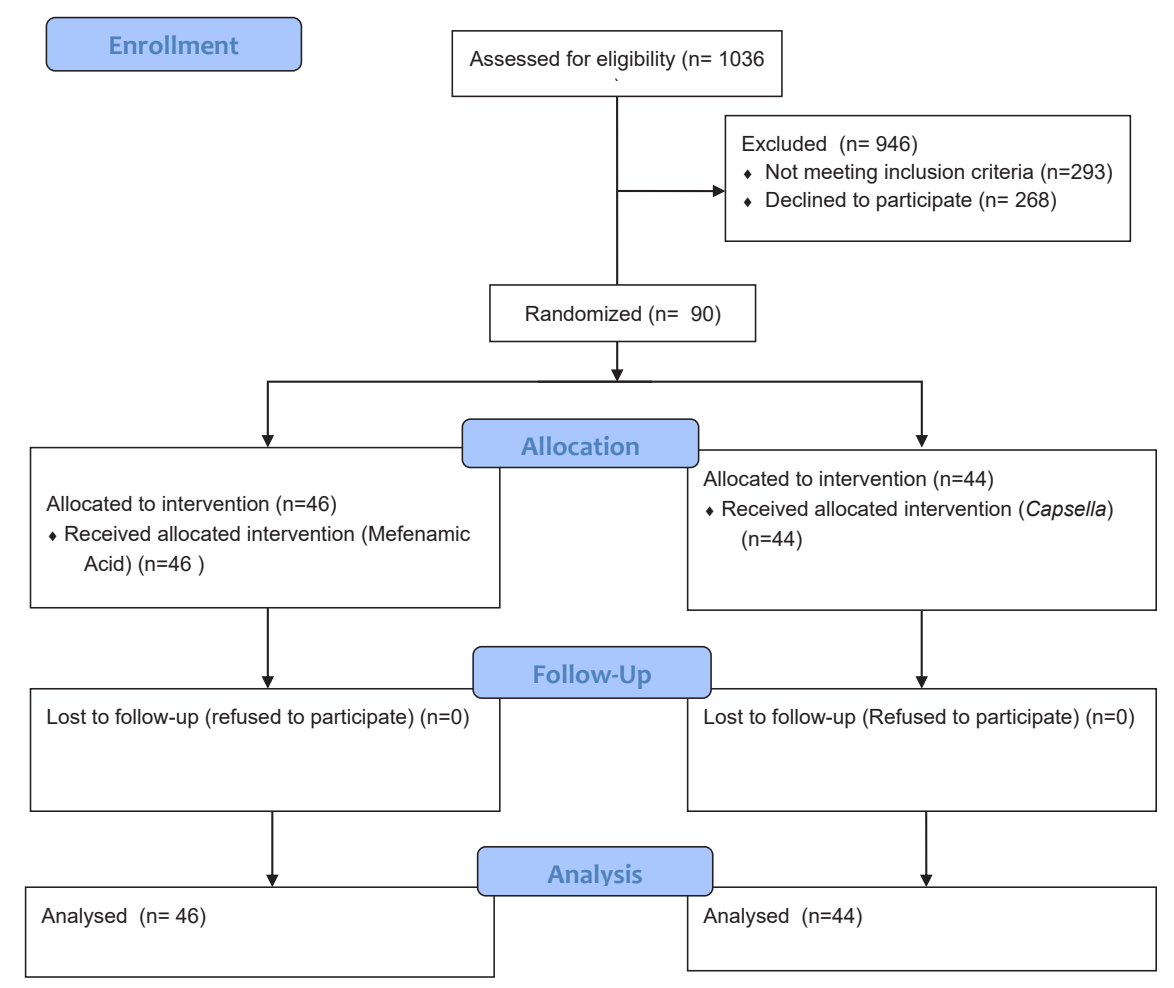

Figure 1. Participant Flow Diagram.

individual-social characteristics $(P>0.05)$. The average age of participants was 31.2 (5.4), most of the participants $(82.2 \%)$ were house wives, and $40 \%$ had high school diploma (Table 1).

The mean of sexual functioning score was 23.39 (4.18) in Mefenamic acid group before intervention, which was increased to 24.24 (3.45) in the third cycle of treatment. In bursa-pastoris group, the mean of sexual functioning was 21.40 (4.70) which was increased to 24.85 (3.81) in the third cycle of treatment (after finishing the intervention). The adjusted difference was 0.60 (95\% CI, -0.19-2.13) after intervention (Table 2).

\section{Discussion}

In spite of fairly high prevalence of sexual functioning problems in females, there have been a few laboratory trials using medicinal interventions for its prevention and treatment (28-30).

The findings of the current study demonstrated that mefenamic acid and bursa-pastoris were both capable of increasing sexual functioning score at the end of third cycle after intervention and this increment was significant in bursa-pastoris group. Due to the lack of studies for investigation of C. bursa-pastoris effect on sexual functioning so far, similar studies were used in the present study (drugs or plants with similar effectual mechanism or similar effective material and disease with similar pathology).

In a study by Amiri et al which was carried out in Tehran, Ginkgo biloba oral capsule led to the improvement of sexual functioning in menopausal females and there was a significant difference among the mean scores of desire to sexual relationship, sexual activity, sexual satisfaction, arousal and orgasm in last month, before and after the use of G. biloba capsule (31). Ito et al in a laboratory triple-blind trial showed that making use of Max arginine supplement which contains G. biloba extraction, multivitamin and minerals, improved sexual satisfaction, sexual desire, vaginal dryness, the number of sexual activity, orgasm and sensitivity of clitoris after 4 weekss (32). In a study which was done by Naafe et al, at Shahid Beheshti University of Medical Sciences in Tehran, it was reported that hydroalcoholic extraction of shoots of bursa-pastoris was effective in reducing menstrual bleeding and treating idiopathic menorrhagia (33). In a study by Sourteji et al, the hydroalcoholic extraction of nettle and mefenamic acid reduced the amount of uterine bleeding and this reduction was significant in nettle group (34).

The bursa-pastoris extraction contains various materials including Tannins, choline, acetylcholine sterols and flavonoids (35). This plant also has oxytocin synergic effects (21). Moreover, IUD reduces the number of intercourse and sexual functioning through increasing irregular uterine bleeding. Therefore, this plant through reducing irregular period bleeding also leads to sexual functioning improvement. Bursa-pastoris like G. biloba contains flavonoids (18) and it seems that it plays an effective role, through similar mechanism, in the improvement of sexual functioning. Furthermore, due to 
Table 1. Individual and Social Characteristics of the Females in Respective Groups Visiting Healthcare Centers of Ardebil in 2015

\begin{tabular}{|c|c|c|c|c|}
\hline \multirow[b]{2}{*}{ Characteristics } & & \multicolumn{2}{|c|}{ Group } & \multirow[b]{2}{*}{$\boldsymbol{P}$} \\
\hline & & Mefenamic Acid ( $n=46$ ) & Capsella bursa-Pastoris $(n=44)$ & \\
\hline \multicolumn{2}{|l|}{ Age $(y)^{*}$} & $30.9(5.2)$ & $31.6(5.7)$ & 0.534 \\
\hline \multirow{5}{*}{ Education level } & Elementary & $8(17.4)$ & 7 (15.9) & \multirow{5}{*}{0.921} \\
\hline & Secondary & $7(15.2)$ & $8(18.2)$ & \\
\hline & High school & $7(15.2)$ & $6(13.6)$ & \\
\hline & Diploma & $10(21.7)$ & $11(25.0)$ & \\
\hline & Graduated & $14(30.4)$ & $12(27.3)$ & \\
\hline \multirow{2}{*}{ Occupation } & Housewife & $37(80.4)$ & $37(84.1)$ & \multirow{2}{*}{0.785} \\
\hline & Employee & $9(19.6)$ & $7(15.9)$ & \\
\hline \multirow{5}{*}{ Husband's education level } & Elementary & $3(6.5)$ & $5(11.4)$ & \multirow{5}{*}{0.310} \\
\hline & Secondary & $10(21.7)$ & $5(11.4)$ & \\
\hline & High school & $8(17.4)$ & $5(11.4)$ & \\
\hline & Diploma & $19(41.3)$ & $17(38.6)$ & \\
\hline & Graduated & $6(13.3)$ & $12(27.3)$ & \\
\hline \multirow{3}{*}{ Husband's occupation } & Unemployed & $6(13.03)$ & $4(9.1)$ & \multirow{3}{*}{0.456} \\
\hline & Self-employed & $27(58.7)$ & $25(56.8)$ & \\
\hline & Employee & 13(28.3) & $15(34.1)$ & \\
\hline \multicolumn{2}{|l|}{ Number of abortions } & $13(28.3)$ & $2(4.5)$ & 0.003 \\
\hline \multicolumn{2}{|c|}{ Curettage Number } & $0(0.0)$ & $3(6.8)$ & 0.113 \\
\hline \multicolumn{2}{|c|}{ Passed time from last maternity * } & $54.5(49.2)$ & $54.6(37.4)$ & 0.609 \\
\hline \multirow{2}{*}{ Lactation } & Yes & $10(21.7)$ & $8(18.2)$ & \multirow{2}{*}{0.794} \\
\hline & No & $36(87.3)$ & $36(81.8)$ & \\
\hline \multirow{2}{*}{$\begin{array}{l}\text { Experience of IUD } \\
\text { insertion }\end{array}$} & Yes & $15(32.6)$ & $10(22.7)$ & \multirow{2}{*}{0.295} \\
\hline & No & $31(67.4)$ & $34(77.3)$ & \\
\hline \multirow{4}{*}{ Reason of IUD removal } & Self-removal & $3(6.5)$ & $4(9.1)$ & \multirow{4}{*}{0.385} \\
\hline & Bleeding & $3(6.5)$ & $0(0.0)$ & \\
\hline & Pain & $1(2.2)$ & $0(0.0)$ & \\
\hline & Pregnant trend & $8(17.4)$ & $6(13.6)$ & \\
\hline \multicolumn{2}{|l|}{ IUD Insertion Time* } & $12.8(10.9)$ & $11.6(9.1)$ & 0.044 \\
\hline
\end{tabular}

All data are represented in \%, except for those identified by *.

Table 2. Average Sexual Function Before and After Intervention in the Studied Groups

\begin{tabular}{lccc}
\hline & \multicolumn{3}{c}{ Group } \\
\cline { 2 - 3 } & $\begin{array}{c}\text { Capsella bursa-Pastoris ( } \mathbf{n}=44) \\
\text { Mean (SD) }\end{array}$ & $\begin{array}{c}\text { Mefenamic Acid (n= 46) } \\
\text { Mean (SD) }\end{array}$ & P Value \\
\hline Before intervention & $22.39(4.18)$ & $21.40(4.70)$ & 0.295 \\
After 3 months & $24.24(3.45)$ & $24.85(3.81)$ & 0.015 \\
\hline
\end{tabular}

having mineral materials, iron, magnesium, vitamins $\mathrm{A}$, $\mathrm{B}$ and $\mathrm{C}$, it can result in increment of sexual functioning like Max arginine supplement. Bursa-pastoris also has inflammatory properties like nettle (1) and it seems effective in bleeding treatment and accordingly in sexual functioning improvement through similar mechanism. The major role of plants in treating some females' illnesses is through their impact on body hormones. The investigations have shown that important combinations of plants including flavonoids directly affect pituitary gland, and cause the increase of pituitary hormones' level (oxytocin) and they can balance disorders which may occur due to the loss of hormones. In addition, oxytocin plays a significant role in human's arousal, increment of orgasm and sexual responses $(22,23)$. According to the findings of this study, C. bursa-pastoris can be effective in abnormal period bleeding reduction and sexual functioning increment at the same level as mefenamic acid which can be a good alternative due to side effects of chemical and non-steroidal anti-inflammatory drugs. This intervention was used for a duration of 3 months on females, but regarding the long-term impact of herbal drugs, it is recommended to carry out the study on sexual functioning for longer periods of time.

\section{Conclusions}

The findings of this study demonstrated that bursapastoris led to the increment of sexual functioning score in copper IUD users. Considering that bursa-pastoris did not have any side effect, and women mostly prefer to take complementary medicines, this plant can be safely used in sexual functioning improvement. 
Table 3. Mean and Standard Deviation of the Obtained Scores From the Sexual Functioning Domains of the Studied Groups in Females Visiting Healthcare Centers of Ardebil in 2015

\begin{tabular}{|c|c|c|c|c|c|c|c|c|}
\hline \multirow{3}{*}{ Groups } & \multicolumn{4}{|c|}{ Before Intervention } & \multicolumn{4}{|c|}{3 Months After Intervention } \\
\hline & \multicolumn{2}{|c|}{ Mefenamic Acid ( $n=46$ ) } & \multicolumn{2}{|c|}{ Capsella bursa-pastoris $(n=44)$} & \multicolumn{2}{|c|}{ Mefenamic Acid ( $n=46$ ) } & \multicolumn{2}{|c|}{ Capsella bursa-pastoris $(n=44$} \\
\hline & Mean & SD & Mean & SD & Mean & SD & Mean & SD \\
\hline Sexual desire & 3.4 & 1.00 & 3.00 & 0.8 & 3.4 & 1.00 & 3.7 & 1.00 \\
\hline Test result & \multicolumn{4}{|c|}{$P=0.033$} & \multicolumn{4}{|c|}{$P=0.042$} \\
\hline Eroticism & 3.7 & 0.8 & 3.6 & 1 & 4.1 & 0.7 & 4.2 & 0.8 \\
\hline Test result & \multicolumn{4}{|c|}{$P=0.531$} & \multicolumn{4}{|c|}{$P=0.187$} \\
\hline Humidifying & 3.8 & 1.2 & 3.7 & 1.2 & 4.2 & 0.9 & 4.00 & 0.9 \\
\hline Test result & \multicolumn{4}{|c|}{$P=0.680$} & \multicolumn{4}{|c|}{$P=0.688$} \\
\hline Orgasm & 3.8 & 1.2 & 3.7 & 1.2 & 4 & 1.00 & 4.2 & 1.1 \\
\hline Test result & \multicolumn{4}{|c|}{$P=0.703$} & \multicolumn{4}{|c|}{$P=0.163$} \\
\hline Sexual satisfaction & 3.6 & 1.1 & 3.5 & 1.2 & 4.1 & 0.9 & 4.3 & 1.1 \\
\hline Test result & \multicolumn{4}{|c|}{$P=0.614$} & \multicolumn{4}{|c|}{$P=0.043$} \\
\hline Pain & 3.9 & 1.2 & 3.8 & 1.5 & 4.2 & 1.00 & 4.6 & 1.0 \\
\hline Test result & \multicolumn{4}{|c|}{$P=0.701$} & \multicolumn{4}{|c|}{$P=0.003$} \\
\hline $\begin{array}{l}\text { Total score of sexual } \\
\text { function }\end{array}$ & 22.3 & 4.2 & 21.3 & 4.8 & 24.2 & 3.4 & 24.8 & 3.8 \\
\hline Test Result & \multicolumn{4}{|c|}{$P=0.301$} & \multicolumn{4}{|c|}{$P=0.032$} \\
\hline
\end{tabular}

\section{Conflict of Interests}

Authors declare that they have no conflict of interests.

\section{Ethical Issues}

The study was obtained by the Ethics Committee of Tabriz University of Medical Sciences (No. 93119). The study was also registered in Iranian Registry of Clinical Trials (http://www.irct.ir/, Identifier: IRCT201412063027N26)..

\section{Financial Support}

This study was supported financially by Tabriz University of Medical Sciences.

\section{Acknowledgments}

This article was part of Master's thesis in Midwifery approved by Research Deputy of Tabriz University of Medical Science.

We are thankful to all the women who participated in the study and also respected Research Deputy of Tabriz University of Medical Sciences that financially assisted us in carrying out the current research.

\section{References}

1. World Contraceptive Patterns 2013. The United Nations website. http://www.un.org/en/development/ desa/population/publications/family/contraceptivewallchart-2013.shtml.

2. Hubacher D, Cheng D. Intrauterine devices and reproductive health: American women in feast and famine. Contraception. 2004;69(6):437-446. doi:10.1016/j. contraception.2004.01.009

3. Kulier R, O'Brien PA, Helmerhorst FM, Usher-Patel M, D’Arcangues C. Copper containing, framed intra-uterine devices for contraception. Cochrane Database Syst Rev. 2007;(4):Cd005347. doi:10.1002/14651858.CD005347. pub3

4. O'Brien PA, Kulier R, Helmerhorst FM, Usher-Patel M,
d'Arcangues C. Copper-containing, framed intrauterine devices for contraception: a systematic review of randomized controlled trials. Contraception. 2008;77(5):318-327. doi:10.1016/j.contraception.2007.12.011

5. Hubacher D, Grimes DA. Noncontraceptive health benefits of intrauterine devices: a systematic review. Obstet Gynecol Surv. 2002;57(2):120-128.

6. Mosher WD, Martinez GM, Chandra A, Abma JC, Willson SJ. Use of contraception and use of family planning services in the United States: 1982-2002. Adv Data. 2004(350):1-36.

7. Khader YS, El-Qaderi S, Khader AM. Intrauterine contraceptive device discontinuation among Jordanian women: rate, causes and determinants. J Fam Plann Reprod Health Care. 2006;32(3):161-164. doi:10.1783/147118906777888279

8. Ghafourian Broujerdnia M, Ayene Band N. Principles of population and family planning. Tehran: Aiezh Publication; 2009.

9. Mehrabi F, Dadfar M. The Role of Psychological Factors in Sexual Functional DisordersIranian Journal of Psychiatry and Clinical Psychology. 2003;9(1):4-11.

10. Frost JJ, Lindberg LD. Reasons for using contraception: perspectives of US women seeking care at specialized family planning clinics. Contraception. 2013;87(4):465472. doi:10.1016/j.contraception.2012.08.012

11. Lethaby A, Duckitt K, Farquhar C. Non-steroidal antiinflammatory drugs for heavy menstrual bleeding. Cochrane Database Syst Rev. 2013(1):Cd000400. doi:10.1002/14651858.CD000400.pub3

12. Safari A, Shah Rezaei GR, Damavandi A. Comparison of the effects of vitamin e and mefenamic acid on the severity of primary dysmenorrhea. Annals Military Health Sciences Research. 2006;4(1):735-738.

13. Parekh J, Chanda SV. Antibacterial activities of aqueous and alcoholic extracts of 34 Indian medicinal plants against some Staphylococcus species. Turk J Biol. 2008;32(1):63-71.

14. Kress H. Book review-Practical Herbs. Australian Journal Medical Herbalism. 2012;24(4):156. 
15. Aksoy A, Dixon JM, Hale WHG. Capsella bursa-pastoris (L.) Medikus (Thlaspi bursa-pastoris L., Bursa bursapastoris (L.) Shull, Bursa pastoris (L.) Weber). J Ecol. 1998;86(1):171-186. doi:10.1046/j.1365-2745.1998.00260.x

16. Charantimath S, Oswal R. Herbal therapy in dentistry: a review. Innov J Med Health Sci. 2011;1(1):1-4.

17. Miraldi E, Ferri S, Mostaghimi V. Botanical drugs and preparations in the traditional medicine of West Azerbaijan (Iran). J Ethnopharmacol. 2001;75(2-3):77-87.

18. Grosso C, Vinholes J, Silva LR, et al. Chemical composition and biological screening of Capsella bursa-pastoris. Revista Brasileira de Farmacognosia. 2011;21(4):635-643. doi:10.1590/S0102-695X2011005000107

19. Livdans-Forret AB, Harvey PJ, Larkin-Thier SM. Menorrhagia: a synopsis of management focusing on herbal and nutritional supplements, and chiropractic. J Can Chiropr Assoc. 2007;51(4):235-246.

20. Mayo JL. A healthy menstrual cycle. Clin Nutr Insights. 1997;5(9):1-8.

21. Moore M. Herbal/Medical Contraindications. Bisbee, AZ: Southwest School Medicine; 1995.

22. Khan-Dawood FS, Yang J, Dawood MY. Potential role of oxytocin in cell to cell communication in the corpus luteum. Adv Exp Med Biol. 1995;395:507-516.

23. Novak E, Berek JS. Berek and Novak's Gynecology. Lippincott Williams Wilkins; 2007.

24. Mirghafourvand M, Mohammad-Alizadeh-Charandabi S, Asghari Jafarabadi M, et al. Socio demographic predictors of marital satisfaction in women of reproductive age, Tabriz, Iran, 2013. Iranian Journal Obstetrics Gynecology Infertility. 2013;16(72):1-12.

25. Moukhah S, Mazari Z, Goshtasbi A, Moaed Mohseni S. The effect of tranexamic acid on the quality of life and blood loss of women with menorrhagia: A clinical trial. Arak Med Univ J. 2012;15(3):75-84.

26. Rosen R, Brown C, Heiman J, et al. The Female Sexual
Function Index (FSFI): a multidimensional selfreport instrument for the assessment of female sexual function. J Sex Marital Ther. 2000;26(2):191-208. doi:10.1080/009262300278597

27. Mohammadi K, Heydari M, Faghihzadeh S. The female sexual function index (fsfi): Validation of the iranian version. Payesh. 2008;7(3):269-278.

28. Diamond BJ, Shiflett SC, Feiwel N, et al. Ginkgo biloba extract: mechanisms and clinical indications. Arch Phys Med Rehabil. 2000;81(5):668-678.

29. Meston CM, Rellini AH, Telch MJ. Short- and long-term effects of Ginkgo biloba extract on sexual dysfunction in women. Arch Sex Behav. 2008;37(4):530-547. doi:10.1007/ s10508-008-9316-2

30. Oh SM, Chung KH. Estrogenic activities of Ginkgo biloba extracts. Life Sci. 2004;74(11):1325-1335.

31. Amiri M, Taavoni S, Seyyed Fatemi N, Haghani H. A comparison between sexual function of menopausal women before and after using Ginkgo biloba capsules. Armaghane Danesh. 2012;17(2):92-101.

32. Ito TY, Trant AS, Polan ML. A double-blind placebocontrolled study of ArginMax, a nutritional supplement for enhancement of female sexual function. J Sex Marital Ther. 2001;27(5):541-549. doi:10.1080/713846828

33. Naafe M, Kariman N, Keshavarz Z, Mojab F, Chaibakhsh S. Considering the effect of hydro alcoholic extract of Capsella bursa-pastoris on menorrhagia. Arak Med Univ J. 2016;19(1):86-94.

34. Sourteji A, Kariman N, Mojab F, Alavi Majd H. Comparison of the effect of mefenamic acid and the hydroalcoholic extract of urtica dioica on the volume of heavy menstrual bleeding in students at Azad University of Babol (20112012). Arak Med Univ J. 2013;16(4):27-36.

35. Song N, Xu W, Guan H, Liu X, Wang Y, Nie X. Several flavonoids from Capsella bursa-pastoris (L.) Medik. Asian J Tradit Med. 2007;2(5):218-222.

(c) 2018 The Author (s); This is an open-access article distributed under the terms of the Creative Commons Attribution License (http://creativecommons.org/licenses/by/4.0), which permits unrestricted use, distribution, and reproduction in any medium, provided the original work is properly cited. 